NOVEL APPROACHES TO THE PRODUCTION OF HIGHER ALCOHOLS FROM SYNTHESIS GAS

Quarterly Technical Progress Report No. 6

For The Period January 1, 1992 to March 31, 1992

\title{
Contractor
}

NORTH CAROLINA STATE UNIVERSITY

DEPAATMENT OF CHEMICAL ENGINEERING

BOX 7905

RALEIGH, NC 27695-7905

George W. Robarts - Program Manager

C. A. Apperson - Contract Coordinatct
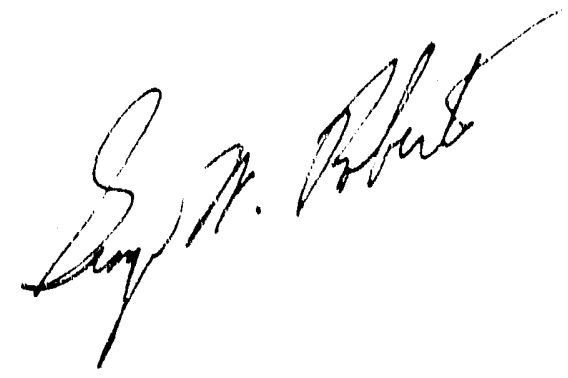

July 8, 1992

Prepared for the United States Department of Energy

Under Contract No. DE-AC22-90PC90043

Contract Period 25 September 1990 - 24 September 1993 
This report was prepared as an account of work sponsored by the United States Government. Neither the United States Department of Energy, nor any of their employees, nor any of their contractors, subcontractors, or their employees, makes any warranty, expressed or implied, or assumes any legal liability or responsibility for the accuracy, completeness, or usefulness of any information, apparatus, product or process disclosed or represents that its use would not infringe privately owned rights. 


\section{NOVEL. APPROACHES TO THE PRODUCTION OF HIGHER \\ ALCOHOLS FROM SYNTHESIS GAS}

Quarterly Technical Progress Report

January 1, 1992 to March 31, 1992

\section{CONTRACT OBJECTIVES}

Task 1. Program Management.

Task 2. Liquid-Phase, Higher Alcohol Process with Recycle of Lower Alcohols.

Task 3. Novel Catalysts for Synthesis of Higher Alcohols.

Task 4. Synthesis of Higher Alcohols via Acid-Base Catalysis.

Task 5. Technology Evaluation.

Technical Progress

- Under Task 2:

Ihermedynamic Calculations

ASPEN simulations examining the potential occurrence of multiple product phases under reaction conditions have been completed. The input to the ASPEN program was structured to permit the formation of up to two ideal product phases, which are in phase equilibrium. As Figure 1 illustrates, at a $2 / 1 \mathrm{H}_{2} / \mathrm{CO}$ ratio, the reactor ouisist stream is entirely a liquid phase below $275^{\circ}$ Celsius, assuming that both chemical and phase equilibrium are achieved. However, any small deviation from the $2 / 1$ ratio results in a mixed gas and liquid product. The two-phase region disappears above $2.78^{\circ} \mathrm{C}$, and the products are all in the vapor phase. The actual boundary between the vapor only region and the two-phase region lies somewhere between the two jagged lines shown in Figure 1. If necessary, the exact boundary could be defined more precisely by carrying out additional calculations at temperatures and $\mathrm{H}_{2} / \mathrm{CO}$ ratios that fal! between the two lines. Closer examination of these results is in progress to provide a solid interpretation and explanation of the product behavior. 
ASPEN computer simulation cases involving methanol, ethanol and propanol recycle have been completed. The results indicate that the yield of higher alcohols increased slightly until the quantity of recycled lower alcohol equaled the amount of that alcohol produced (i.e. When there is no net formation of the recycled alcohol). Above this point, no change in higher alcohol yieid was observed. All cases were based on a $2 / 1 \mathrm{H}_{2} / \mathrm{CO}$ feed ratio at $70 \mathrm{~atm}$ and $275^{\circ} \mathrm{C}$.

ASPEN PLUS simulations of the thermodynamics of higher alcohol synthesis were carried out based on non-ideal, equation-of-state models. The models used were the Peng-Robinson and the Redlich-Kwong-Aspen equations of state. The results of these simulations indicate ery little difference between the results obtained with the ideal fluid model and the non-ideal models. No significant changes were found in reactant conversion, product distribution or product yield.

A paper was prepared for presentation at the American Chemical Society Symposium on Natural Gas Upgrading in April, 1992. A copy of the paper is attached.

\section{Laboratery Construction}

All laboratory renovations are now complete. The gas lines running from the ground floor gas station to the third floor laboratory (Room 303) were completed. Only a single leak was found during pressure testing. The leak was repaired and the gas lines held $450 \mathrm{psig}$ with no pressure loss for 24 hours. Since these gas lines could experience full gas cylinder pressure if a valve failure occurred, they were also tested for 2 hours at 2000 psig. No leaks were detected. The water, air and drainage lines were relocated, and the electrical wiring was installed.

The walk-in hood was completed. The duct from the fan to the hood was installed. A smoke test determining air flow pattems in the hood was conducted by the University Life Safety Department, and several cross drafts caused by leaks at the wall were discovered. The hood was subsequently sealed at all wall and floor joints to eliminate the irregular flow patterns.

The gas station flow control panel, including solenoid valves, check valves, pressure regulators, and hydrocarbon traps, was installed in the gas 
station. Installation of remote control panels for the solenoid valves was also completed. The panels, located in Room 303, allow manual control of the solenoid valves in froom 303 and in the gas station on the ground floor.

The excess flow valves, designed to shut off gas flow in the event of a line rupture, were tested and did not close at the required flow rates. The valves were returned to Veriflo for reconfiguration. Delays by Veriflo have pushed the return date to April.

The full reactor system was pressure tested at 4500 psig and several leaks were found. A pressure regulator became inoperative after expusure to the high pressure. Replacement parts will arrive in April. The laboratory safety plan was completed; work on standard job procedures is continuing.

- Under Task 3:

\section{EXAFS Studies of Experimental Catalysts}

Trips were made to Brookhaven National Labs to run extended $x$-ray absorption fine structure (EXAFS) spectroscopy in mid-danuary and late March. The catalyst samples prepared for the trips were composed of modium-niobium on alumina, including a new sample that utilized the acidic character of the oxides to selectively deposit the rhodium precursor on the support. The EXAFS spectroscopy data has improved with each visit to Brookhaven due to the stabilization of the mono-chromator crystal cooling water temperature. Past problems with control of this temperature caused periodic oscillations in the data.

- Under Task 4:

\section{Methanol TPQ}

Ternperature progr'sinmed descrption (TPD) of methanol was carried out to observe the pinduct distribution as a function of temperature on various catalysts at atmospheric pressure. ZSM-5, mordenite, alurnina $\left(\mathrm{Al}_{2} \mathrm{O}_{3}\right)$, $\mathrm{Cu} / \mathrm{Al}_{2} \mathrm{O}_{3}$, and silica-alunina catalysts woro tested. Catalysts were dehydrated under $30 \mathrm{cc} / \mathrm{min}$ flowing $\mathrm{Ho}$ for $1 \mathrm{hr}$. at $200^{\circ} \mathrm{C}$. Methanol was then adsorbed on the catalyst at $40^{\circ} \mathrm{C}$ and TPD was nu atmospheric prossure using mass spectrometry (MS) for the analysis of desorbed products. 
Dimethylether (DME) was observed to desorb from the zeolites and $\mathrm{Cu} / \mathrm{Al}_{2} \mathrm{O}_{3}$ at $170^{\circ} \mathrm{C}$ and from alumina at $220^{\circ} \mathrm{C}$. A second DME peak was observed on zeolites at $270^{\circ} \mathrm{C}$. On alumina, methane, carbon monoxide $(\mathrm{CO})$ and some hydrogen desorbed at $410^{\circ} \mathrm{C} . \mathrm{C}^{+} 2$ products were not observed on alumina. Thus, a thermal decomposition of methoxyl species and DME apparently took place on the weak lewis acid site: of alumina at high temperature. Alumina did not show any activity for the formation of higher hydrocarbons.

On high alumina zeolites, methane, ethylene, and propylene desorbed at $300^{\circ} \mathrm{C}$. Hydrogen and CO ware not observed. On high silica zeolites, only ethylene and propylene desorbed at $270^{\circ} \mathrm{C}$. Methane, hydrogen, and CO were not observed. On $\mathrm{Cu} / \mathrm{Al}_{2} \mathrm{O}_{3}$, hydrogen, methane, ethylene, propylene, and DME were observed at $220^{\circ} \mathrm{C}$.

The strong bronsted acid sites on high-silica zeolites appear to be necessary to dehydrate and simultaneously transtorm DME to higher hydrocarbons. Bronsted acid sites of intermediate strength on high alumina zeolites form methane in addition to higher hydrocarbons. Weak lewis acid sites on alumina can simply dehydrate and decompose methoxyl species and DME to CO, methane, and hydrogen, without the formation of higher hydrocarbons.

$\mathrm{Cu} / \mathrm{Al}_{2} \mathrm{O}_{3}$ forms hydrogen and hydrocarbons, possibly by a rodox mechanism.

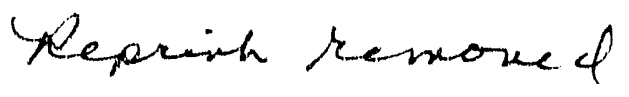


Figure 1

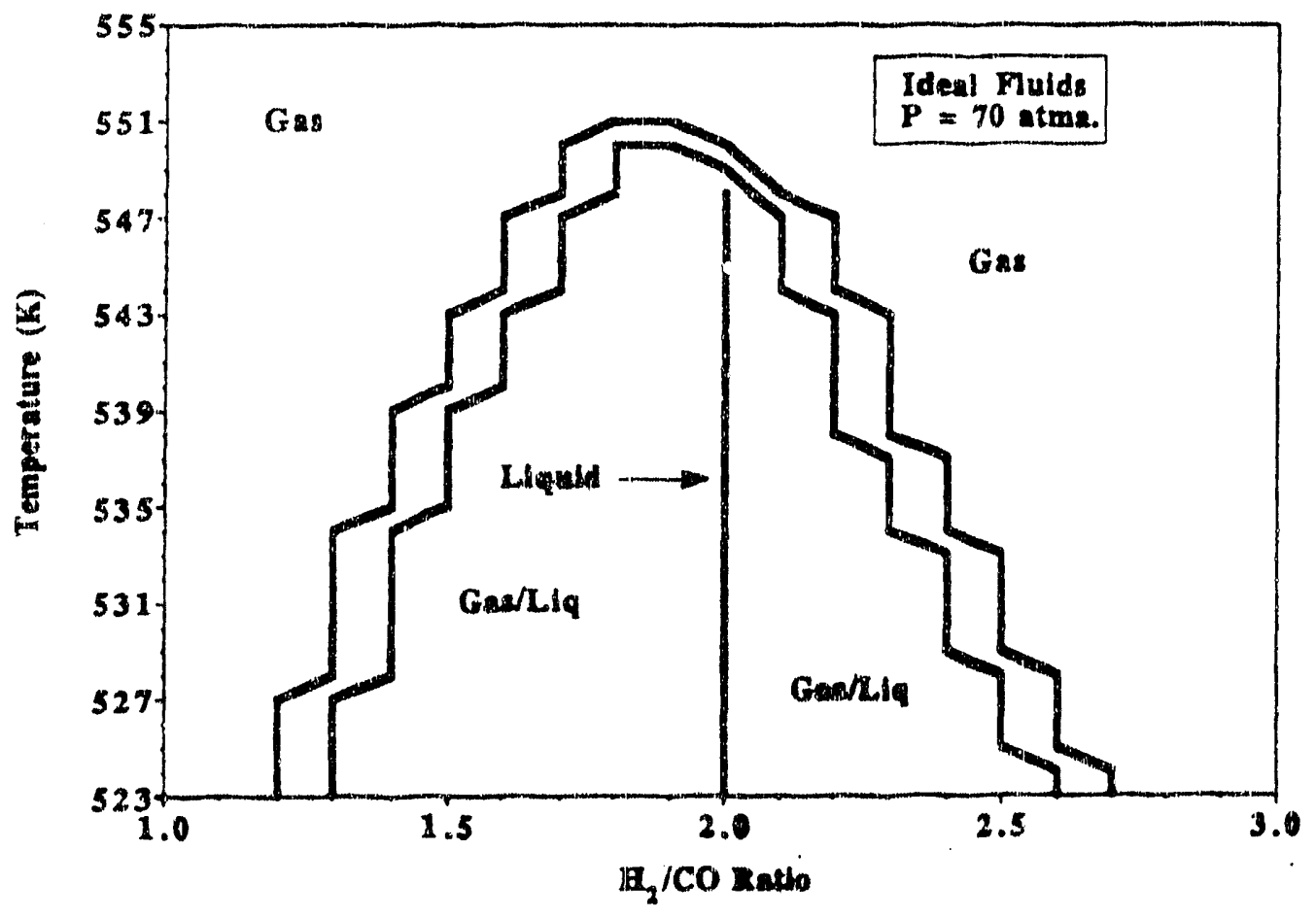



